\title{
Fluorescent and Colorimetric Electrospun Nanofibers for Heavy-Metal Sensing
}

\author{
Idelma A. A. Terra ${ }^{1,+}$, Luiza A. Mercante ${ }^{1,2,+}$ (D), Rafaela S. Andre ${ }^{1,+}$ and Daniel S. Correa ${ }^{1,3, *}$ \\ 1 Nanotechnology National Laboratory for Agriculture (LNNA), Embrapa Instrumentação, \\ São Carlos 13560-970, SP, Brazil; iaterra@yahoo.com.br (I.A.A.T); lamercante@gmail.com (L.A.M.); \\ lela_rsa@hotmail.com (R.S.A.) \\ 2 PPG-CEM, Department of Materials Engineering, Center for Exact Sciences and Technology, \\ Federal University of São Carlos (UFSCar), São Carlos 13565-905, SP, Brazil \\ 3 PPGQ, Department of Chemistry, Center for Exact Sciences and Technology, \\ Federal University of São Carlos (UFSCar), São Carlos 13565-905, SP, Brazil \\ * Correspondence: daniel.correa@embrapa.br; Tel.: +55-16-2107-2800 \\ + These authors contributed equally to this work.
}

Received: 26 October 2017; Accepted: 13 December 2017; Published: 15 December 2017

\begin{abstract}
The accumulation of heavy metals in the human body and/or in the environment can be highly deleterious for mankind, and currently, considerable efforts have been made to develop reliable and sensitive techniques for their detection. Among the detection methods, chemical sensors appear as a promising technology, with emphasis on systems employing optically active nanofibers. Such nanofibers can be obtained by the electrospinning technique, and further functionalized with optically active chromophores such as dyes, conjugated polymers, carbon-based nanomaterials and nanoparticles, in order to produce fluorescent and colorimetric nanofibers. In this review we survey recent investigations reporting the use of optically active electrospun nanofibers in sensors aiming at the specific detection of heavy metals using colorimetry and fluorescence methods. The examples given in this review article provide sufficient evidence of the potential of optically electrospun nanofibers as a valid approach to fabricate highly selective and sensitive optical sensors for fast and low-cost detection of heavy metals.
\end{abstract}

Keywords: electrospinning; optical sensors; heavy metals

\section{Introduction}

The accelerated deterioration of the environment caused by pollutants produced due to rapid industrialization and urbanization has become a serious global challenge that is predicted to become worse in the future [1-5]. In this scenario, heavy metals appear as pollutants of immense biological and environmental concern as they are nondegradable and tend to accumulate in ecological systems and in the food chain, causing serious problems for the environment and human health [4-8]. The accumulation of such metals in the human body can cause severe damage to mucus tissue, the intestinal tract, the skeletal system, the central nervous system, the liver, kidneys and reproductive systems $[3-5,7]$.

Maximum permissible levels of heavy metal ions in the environment have been recommended by several environmental agencies including the World Health Organization (WHO), US Environmental Protection Agency (EPA) and European Medical Agency (EMA) [7,9]. In general, most of these permissible limits fall in the range from ppt to ppm levels [3,5]. Therefore, the development of rapid and inexpensive strategies for sensing heavy metals for the early detection of pollution in living systems and in the environment becomes highly desirable. 
Traditional analytical methods such as atomic absorption spectroscopy (AAS), inductively coupled plasma-mass spectrometry (ICP-MS), inductively coupled plasma-optical emission spectroscopy (ICP-OES), mass spectrometry (MS) and X-ray fluorescence spectroscopy (XPS) can provide accurate quantitative information on metal ions, but their application can be hampered by expensive equipment, complex procedures and inflexibility for on-site analysis [4,10]. In light of these drawbacks, emphasis is currently being placed on the development of sensor devices that offer high sensitivity, short response times, and selectivity for the in-situ/on-site screening of metal ions. Potential candidates to meet these requirements include laser-induced breakdown spectroscopy (LIBS) [11], and electrochemical [12] and optical [13] techniques. Among them, optical sensors that allow on-site and real-time detection without the use of any complicated spectroscopic instrumentation have received great attention for the biosensing of different pollutant species [10,14-17].

The successful development of a sensible and robust optical chemical sensor is intrinsically related to the nature of the platform on which it is constructed $[6,18,19]$. With recent advances in nanomaterials, new strategies are emerging to design novel optical biosensor platforms. These materials can lead to significant improvement in the performance of sensors in terms of sensitivity, selectivity, multiplexed detection capability and portability [3,4]. To date, various nanomaterials, such as graphene and graphene oxide, quantum dots, carbon nanotubes, and metallic and magnetic nanomaterials, have been successfully exploited for designing sensors relying on different optical signal transduction systems [4,15].

Compared with other nanomaterials, nanofibers obtained by electrospinning can be applied in optical sensors with several advantages including easy fabrication and functionalization, low cost, easy detection, and customized properties, such as chemical composition, structure, morphology, porosity and diameter [14-16,20-22]. In addition, considering that the electrospun nanofibers (ESNFs) are obtained as membranes/mats and can be taken out after the detection process, optical sensors based on ESNFs do not contaminate the detection solution and allow easy post-treatment after the detection process $[14,15,20]$.

The possibility to build up multifunctional nanostructures by functionalizing the nanofibers with a wide range of optically active materials, as illustrated in Figure 1, allows the electrospinning technique to design optical biosensors with improved performance [20]. Optically active ESNFs can be obtained using three main approaches: (i) by embedding absorbing or luminescent chromophores or NPs into transparent and optically inert polymers; (ii) by using conjugated polymers, which can intrinsically absorb/emit light and (iii) by attaching optically active nanosystems to the polymer surface through suitable chemical functionalization [17].

The most common methods applied for the optical sensing of heavy metals using ESNFs are those based on light absorption or light emission. Absorption or colorimetric sensing is accomplished using an indicator that changes its color upon binding to the analyte; this change is not only spectroscopically determined but can also be visible. In light-emission methods, the analyte concentration is determined by the change in the emission properties of a fluorophore after being excited by a defined wavelength [23]. Therefore, this paper reviews the recent progress on the development of ESNF-based optical sensors using colorimetric or fluorescent methods for the determination of heavy metals. Here we intend to give the readers a detailed evaluation on the distinct optically active electrospun nanofibers based approaches employed for the analysis of some hazardous metal ions (i.e., $\mathrm{Fe}(\mathrm{III}), \mathrm{Hg}$ (II), $\mathrm{Cu}$ (II), $\mathrm{Ni}(\mathrm{II}), \mathrm{Cr}(\mathrm{III})$ and $\mathrm{Pb}$ (II)). The prominent examples, reported in the last five years, of fluorescent and colorimetric electrospun nanofibers used for heavy-metal detection, are summarized in Tables 1 and 2. Firstly, we present some examples of optical sensors based on fluorescent ESNFs, and then, colorimetric detection of heavy metals based on ESNFs functionalized with organic molecules, nanoparticles and conjugated polymers are overviewed. Finally, the review indicates trends and directions regarding the latest advances in the development of electrospun nanofibers for optical detection of hazardous ions. 
Table 1. Recent representative examples reported in the last five years of fluorescent-based electrospun nanofibers (ESNFs) for heavy-metal detection.

\begin{tabular}{|c|c|c|c|c|}
\hline Analyte & Polymeric matrix & Recognition material & LOD $\left(\mathrm{mg} \cdot \mathrm{L}^{-1}\right)$ & Reference \\
\hline \multicolumn{5}{|l|}{ Single detection } \\
\hline \multirow[t]{5}{*}{$H g(I I)$} & PCL & AuNC & $5.0 \times 10^{-8}$ & [24] \\
\hline & $\mathrm{EC}$ & EMIMBF4 & $1.4 \times 10^{-5}$ & [25] \\
\hline & poly(MMA-co-BNPTU-co-RhBAM) & BNPTU & $4.0 \times 10^{-3}$ & [26] \\
\hline & PAN & DTPDI & $1.0 \times 10^{-3}$ & [27] \\
\hline & poly(NIPAAm-co-NMA-co-AA) & BNPTU & $2.0 \times 10^{-2}$ & [28] \\
\hline \multirow[t]{2}{*}{$\mathrm{Fe}(\mathrm{III})$} & PAN & CDs & 0.2 & [29] \\
\hline & poly(HEMA-co-NMA-co-NBD) & $\mathrm{SRhBOH}$ & 5.6 & [30] \\
\hline $\mathrm{Ni}(I I)$ & PAN-PAA & PAN-PAA & $7.0 \times 10^{-3}$ & [31] \\
\hline \multirow[t]{5}{*}{$\mathrm{Cu}(I I)$} & PMMA & $\mathrm{CsPbBr}_{3}$ QDs & $6.0 \times 10^{-11}$ & [32] \\
\hline & PNNR & PNNR & $6.4 \times 10^{-3}$ & [33] \\
\hline & CA & DTT.AuNC & $5.0 \times 10^{-2}$ & {$[34]$} \\
\hline & poly(MMA-co-AHPA) & RhB-hydrazine & $9.5 \times 10^{-2}$ & [35] \\
\hline & poly(NIPAAm-co-NMA) & F-phen & - & [36] \\
\hline$A l(I I I)$ & PU & $\mathrm{R} 2 \mathrm{PP}$ & $2.0 \times 10^{-4}$ & [37] \\
\hline \multicolumn{5}{|l|}{ Multiple detection } \\
\hline $\mathrm{Cu}(\mathrm{II}) / \mathrm{Cr}(\mathrm{III})$ & CA & 1,4-DHAQ & $2.0 \times 10^{-4}$ for $\mathrm{Cu}(\mathrm{II})$ and $\mathrm{Cr}(\mathrm{III})$ & [38] \\
\hline Co(II)/Zn(II) & $\mathrm{PU}$ & DS-5N, FL-5N and NBD-5N & 2.0 for $\mathrm{Co}(\mathrm{II})$ and 3.0 for $\mathrm{Zn}(\mathrm{II})$ & [39] \\
\hline $\mathrm{Fe}(\mathrm{III}) / \mathrm{Cr}(\mathrm{III}) / \mathrm{Hg}(\mathrm{II})$ & PVA & SRD and SSRD & $\begin{array}{c}5.6 \times 10^{-2} \text { for } \mathrm{Fe}(\mathrm{III}), 5.2 \times 10^{-2} \text { for } \\
\mathrm{Cr}(\mathrm{III}) \text { and } 0.1 \text { for } \mathrm{Hg}(\mathrm{II})\end{array}$ & [40] \\
\hline $\mathrm{Pb}(\mathrm{II}) / \mathrm{Hg}(\mathrm{II}) / \mathrm{Fe}(\mathrm{III}) / \mathrm{M} n(\mathrm{II}) / \mathrm{Ni}(\mathrm{II}) / \mathrm{Cd}(\mathrm{II})$ & PAN & CPEs & - & [41] \\
\hline \multicolumn{5}{|c|}{ 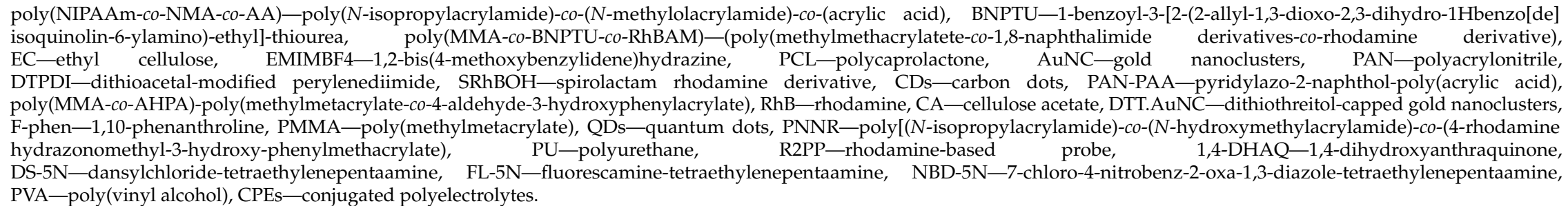 } \\
\hline
\end{tabular}

PVA—poly(vinyl alcohol), CPEs—conjugated polyelectrolytes. 


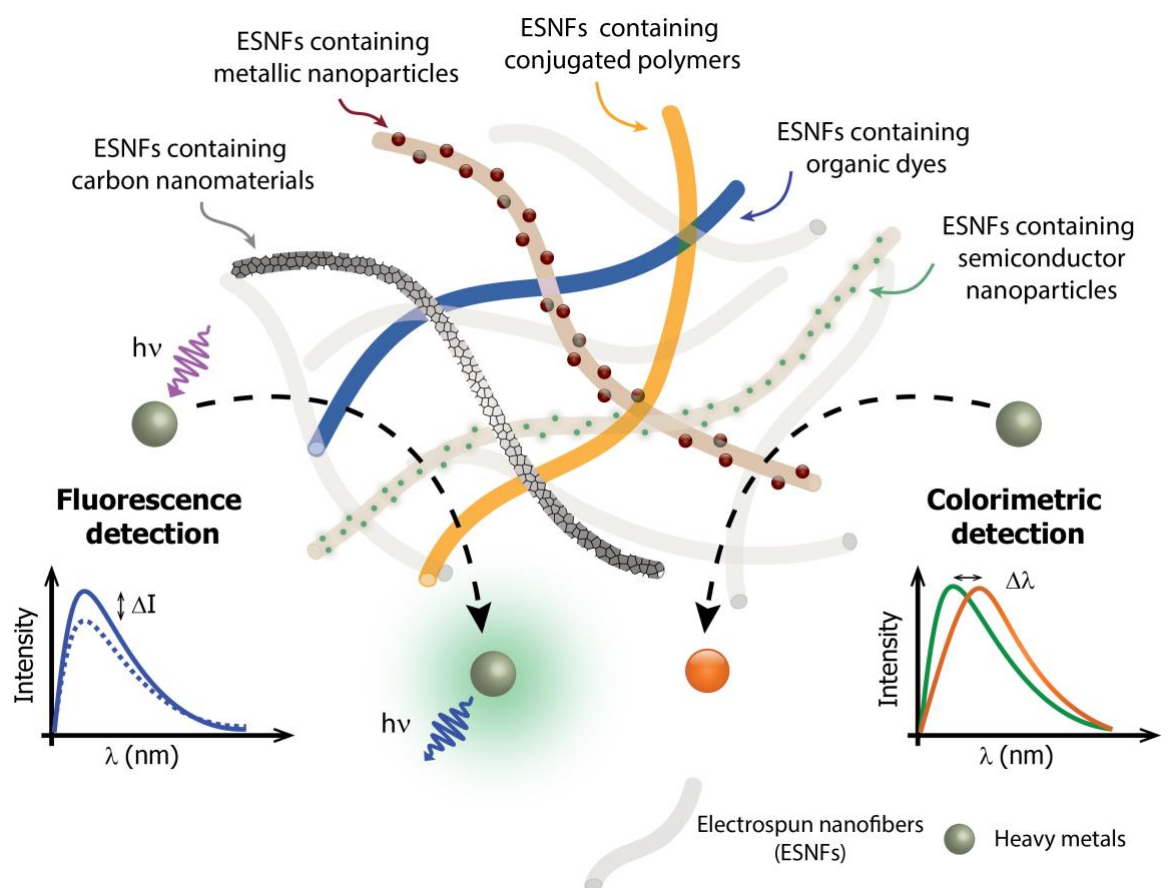

Figure 1. Scheme of electrospun nanofibers (ESNFs) modified by distinct nanomaterials for applications in optical sensors for heavy-metal detection. The lower part of the figure provides a schematic showing the principles of optical detection by the fluorescence quenching (left) or by the color change (right) of the ESNFs in the presence of the heavy metal ion.

Table 2. Recent representative examples reported in the last five years of colorimetric-based ESNFs for heavy-metal detection.

\begin{tabular}{|c|c|c|c|c|}
\hline Analyte & Polymeric Matrix & Recognition Material & LOD (mg. $\left.\mathrm{L}^{-1}\right)$ & Reference \\
\hline \multirow{4}{*}{$\mathrm{Pb}(\mathrm{II})$} & CA & PMDA & $1.0 \times 10^{-2}$ & [42] \\
\hline & PAN & PCDA and PCDA-5EG & $1.0 \times 10^{-1}$ & [43] \\
\hline & PA6/PVDF & Au@GSH NPs & $1.0 \times 10^{-1}$ & [44] \\
\hline & CA & curcumin & 4.1 & [45] \\
\hline \multirow{2}{*}{$H g(I I)$} & PVA & AuNC & $1.0 \times 10^{-3}$ & [46] \\
\hline & PA6/PVB & PANI & $1.0 \times 10^{-3}$ & [47] \\
\hline $\mathrm{Ni}(I I)$ & N6 & DMG & $2.0 \times 10^{-3}$ & [48] \\
\hline $\mathrm{Fe}(I I I)$ & Zein & curcumin & $4.0 \times 10^{-1}$ & [49] \\
\hline $\mathrm{Fe}(\mathrm{II})$ & PVBC & PIMH & $1.0 \times 10^{-4}($ solution $)$ and $2.0 \times 10^{-3}($ solid state $)$ & [50] \\
\hline
\end{tabular}

PAN-polyacrylonitrile, PCDA-10,12-pentacosadiynoic acid, PCDA-5EG-10,12-pentacosadiynoic acid-pentaethylene glycol, PA6-polyamide-6, PVDF—polyvinylidene, Au@GSH NPs—L-glutathione-conjugated gold nanoparticles, CA-cellulose acetate, PMDA - pyromellitic dianhydride, PVA-poly(vinyl alcohol), AuNC—gold nanoclusters, PVB—polyvinylbutyral, PANI—polyaniline, PVBC—poly(vinylbenzyl chloride), PIMH-2-(2'-pyridyl)imidazole.

\section{Electrospun Nanofiber-Based Optical Sensors for Heavy-Metal Detection}

\subsection{Optical Detection Using Fluorescence}

Luminescence is the phenomenon of light emission by a substance that was not strongly heated, where the emission is not associated with thermal radiation. Depending on the nature of the excited state and emission rates (lifetime), luminescence is divided into two categories, namely fluorescence and phosphorescence. The theoretical background of some of the main optical mechanisms employed in optical sensors, such as fluorescence quenching, Stokes shift and resonance energy transfer (RET), are fundamental concepts that allow the analysis of different properties of materials [31,51-53]. The high sensitivity provided by fluorescence is an important feature for sensing materials applied in optical sensors for varied applications. 
In this topic, we discuss some of the most recent work that employed electrospun nanofibers for different heavy-metal sensing through optical detection using fluorescence. In recent work, $\mathrm{Ma}$ and coworkers [27] reported the fabrication of fluorescent nanofibrous membrane (NFM) using the electrospinning technique. The NFMs were obtained through immobilization of dithioacetal-functionalized perylenediimide (DTPDI) on hydrolyzed polyacrylonitrile (PAN) nanofiber membranes, as illustrated in Figure 2a (i). When the NFMs were immersed in $\mathrm{Hg}$ (II) aqueous solution, the reaction of the DTPDI with $\mathrm{Hg}$ (II) takes place, due to the sulfur-mercury affinity. Consequently, the C-S-C bonds of DTPDI were broken to produce hydrolysate, which was adsorbed on DTPDI through $\pi-\pi$ stacking. The selectivity of NFM was analyzed with $\mathrm{K}(\mathrm{I}), \mathrm{Na}(\mathrm{I}), \mathrm{Mg}(\mathrm{II}), \mathrm{Ca}(\mathrm{II}), \mathrm{Cu}(\mathrm{II})$, $\mathrm{Zn}(\mathrm{II}), \mathrm{Fe}(\mathrm{II}), \mathrm{Fe}(\mathrm{III})$ and $\mathrm{Cr}$ (III) ions (Figure 2a (ii)). The high sensitivity and selectivity toward $\mathrm{Hg}$ (II) were observed in the absorbance measured of the NFMs, where there is an increase of intensity as a function of $\mathrm{Hg}$ concentration, with a detection limit of $1.0 \times 10^{-3} \mathrm{mg} \cdot \mathrm{L}^{-1}$ for $\mathrm{Hg}$ (II) in water (Figure $2 \mathrm{a}$ (iii)). The study demonstrated that the sensing of NFMs with $\mathrm{Hg}$ (II) was reversible and stable, while the selectivity of chemosensing was evaluated for different heavy metal ions, with no relevant interference.
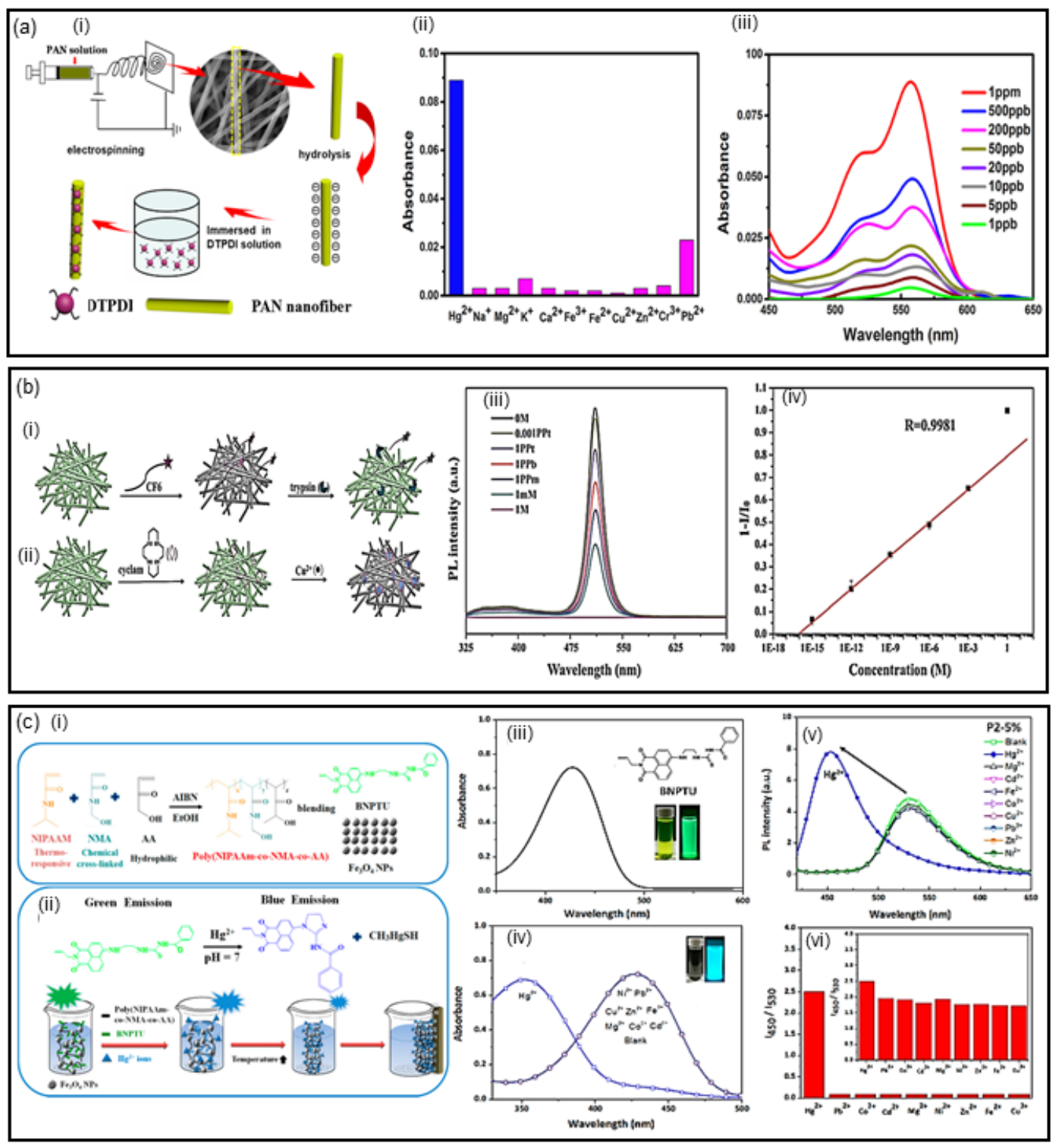

Figure 2. Cont. 

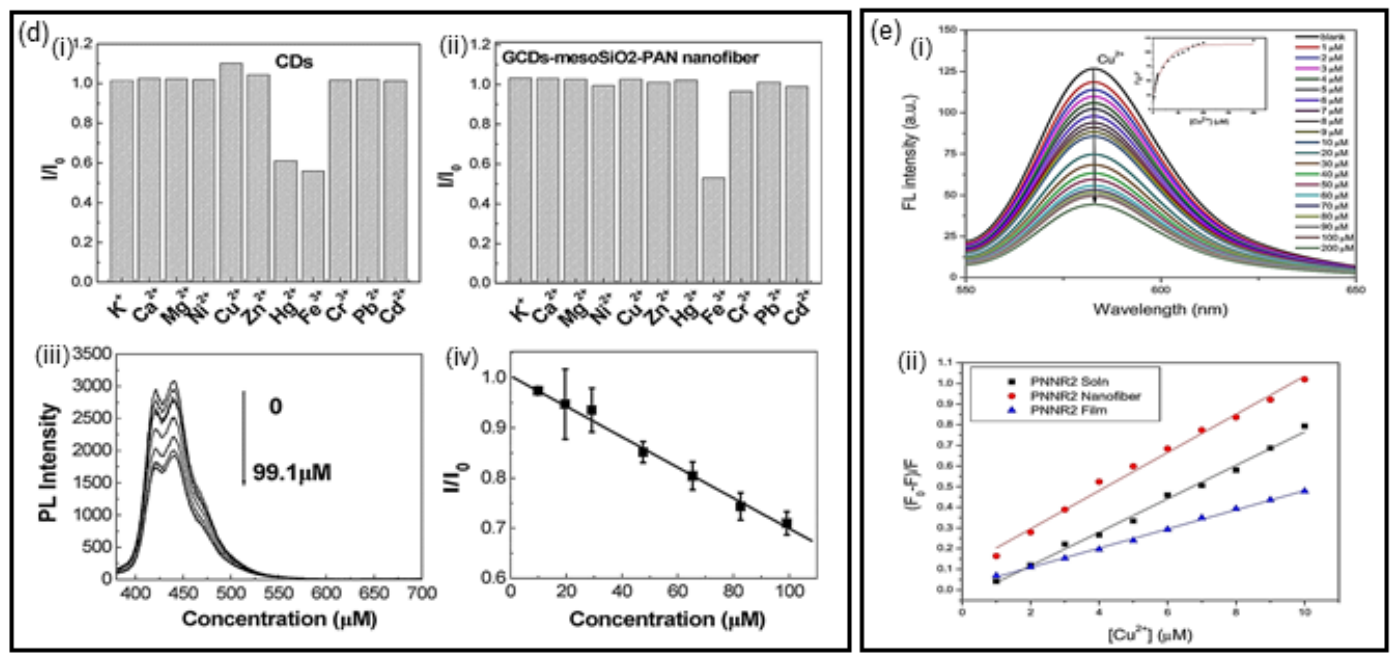

Figure 2. (a) (i) Schematic representation for the fabrication of fluorescent nanofibrous membrane (NFM), (ii) absorbance of FNFM after being immersed into the aqueous solution of metal ions and (iii) UV-vis absorption spectra in the presence of $\mathrm{Hg}(\mathrm{II})$ with various concentrations. Adapted and reprinted with permission from [27]. Copyright 2017 Elsevier. (b) Schematic illustration of (i) trypsin and (ii) $\mathrm{Cu}$ (II) sensing based on the CPBQD/PMMA $\left(\mathrm{CsPbBr}_{3}\right.$ perovskite quantum dots/polymethylmethacrylate), (iii) Photoluminescence (PL) spectra of the CPBQD/PMMA in an aqueous medium of different $\mathrm{Cu}$ (II) concentrations and (iv) relationship between the PL intensity and $\mathrm{Cu}(\mathrm{II})$ concentration. Reprinted with permission from [32]. Copyright 2017 Royal Society of Chemistry. (c) (i and ii) Schematic illustration of multifunctional sensory electrospun nanofibers (ESNFs) synthesized from poly(NIPAAm-co-NMA-co-AA), 1-benzoyl-3-[2-(2-allyl-1,3-dioxo-2,3-dihydro-1Hbenzo[de]isoquinolin-6-amino)-ethyl]-thiourea (BNPTU) and $\mathrm{Fe}_{3} \mathrm{O}_{4}$ blends with magnetic fluorescence emission, (iii) absorption spectra, (iv) variation of absorption spectra for different metal ions, (v) variation in the normalized PL spectra for different metal ions and (vi) fluorometric response ESNFs. Reprinted with permission from [28]. Copyright 2017 MDPI. (d) (i) Schematic illustration of the selectivity of carbon quantum dot (CD), (ii) $\mathrm{CD} / \mathrm{mesoSiO}_{2} / \mathrm{PAN}$ nanofibers for $\mathrm{Fe}(\mathrm{III})$ detection, (iii) PL response and (iv) linear fit of the PL intensity towards $\mathrm{Fe}(\mathrm{III})$ of the $\mathrm{CD} / \mathrm{mesoSiO}_{2} / \mathrm{PAN}$ nanofibers. Reprinted with permission from [29]. Copyright 2016 Springer. (e) (i) Fluorescence spectra of PNNR2 solution in methanol/Tris-HCl for different concentrations of $\mathrm{Cu}(\mathrm{II})$ ions and (ii) Stern-Volmer plots of PNNR2 in different states for $\mathrm{Cu}(\mathrm{II})$ detection. Adapted and reprinted with permission from [33]. Copyright 2016 Springer.

Electrospun fiber membranes as multifunctional sensors for biomolecules, metal ions and $\mathrm{pH}$ have attracted attention. In this direction, Wang et al. [32] developed multifunctional ESNFs based on $\mathrm{CsPbBr}_{3}$ perovskite quantum dots (CPBQDs) encapsulated into polymethylmethacrylate (PMMA) electrospun nanofibers (CPBQD/PMMA). The detection of trypsin, $\mathrm{Cu}(\mathrm{II})$ and $\mathrm{pH}$ was based on the efficient fluorescence resonance energy transfer (FRET) process occurring between CPBQD/PMMA ESNFs and Rhodamine 6G (R6G) or cyclam, respectively, due to the high quantum yield (88\%) of CPBQD/PMMA ESNFs (Figure 2b (i) and (ii)). Such a feature enables the high-efficiency FRET process between the CPBQD/PMMA and $\mathrm{Cu}(\mathrm{II})$ after attaching cyclam, which is used as the probe for $\mathrm{Cu}(\mathrm{II})$. The detection of $\mathrm{Cu}(\mathrm{II})$ by CPBQD/PMMA FM (fibermembrane)-cyclam is measured by quenching PL (Figure 2b (iii)), which occurs due to the absorption band of cyclam-Cu(II) at $520 \mathrm{~nm}$ matching the emission band of the CPBQD/PMMA FM. This behavior leads to a detection limit of $6.0 \times 10^{-11} \mathrm{mg} \cdot \mathrm{L}^{-1}$ for $\mathrm{Cu}(\mathrm{II})$ in aqueous medium, highly suitable for real sample analysis. The selectivity test showed that the CPBQD/PMMA-cyclam is specific to $\mathrm{Cu}$ (II) compared with the same concentration of $\mathrm{Zn}(\mathrm{II}), \mathrm{Mn}(\mathrm{II}), \mathrm{Cr}(\mathrm{II}), \mathrm{Fe}(\mathrm{II}), \mathrm{Co}(\mathrm{II}), \mathrm{Na}(\mathrm{I})$ and $\mathrm{K}(\mathrm{I})$ ions, due to the low-efficiency FRET processes between the CPBQD/PMMA and these ions. 
Another multifunctional fluorescent ESNF was reported by Liang et al. [28], obtained by the combination of poly ( $N$-isopropylacrylamide)-co-( $N$-methylolacrylamide)-co-(acrylic acid), the fluorescent probe 1-benzoyl-3-[2-(2-allyl-1,3-dioxo-2,3-dihydro-1Hbenzo[de]isoquinolin-6-amino) -ethyl]-thiourea (BNPTU) and magnetite nanoparticles (NPs), as displayed in Figure 2c (i and ii). The produced NFMs exhibited high sensitivity toward magnetism, temperature and mercury ions $(\mathrm{Hg}(\mathrm{II}))$. The limit of detection of $2.0 \times 10^{-2} \mathrm{mg} \cdot \mathrm{L}^{-1}$ for $\mathrm{Hg}(\mathrm{II})$ in aqueous solution was obtained by absorbance and photoluminescence measurements, where a blue-shift of maximum emission was noted (Figure 2c (iii and v)). High selectivity and sensitivity for $\mathrm{Hg}(\mathrm{II})$ was observed compared to different metals (Figure 2c (iv and vi)). The same blue-shift was observed by fixing the $\mathrm{Hg}$ (II) concentration and varying the temperature between 30 and $60{ }^{\circ} \mathrm{C}$. The blue-shift was observed due to the $\mathrm{Hg}$ (II) ion transforming the thiourea unit of BNPTU into an imidazoline moiety, which has weak electron-donating ability (Figure 2c (i)). On the other hand, a change in the absorption and photoluminescence (PL) peak for other metal ions was not observed (Figure $2 \mathrm{c}$ (iv)), ensuring the selectivity for $\mathrm{Hg}$ (II) ion. The magnetic fluorescent ES nanofibers can be used as naked-eye sensors for accessible and practical applications as multifunctional sensing devices.

Li et al. [29] reported the development of carbon quantum dot (CD)-encapsulated mesoporous silica/polyacrylonitrile $\left(\mathrm{CD} / \mathrm{mesoSiO}_{2} / \mathrm{PAN}\right)$ electrospun nanofibers. The use of $\mathrm{CDs}$ has been explored in various areas, owing to their excellent physical and chemical properties. By encapsulation of the CDs into the polymer nanofiber, the authors preserved the CDs' sensory capabilities, improving sensibility and stability of material. $\mathrm{CD} / \mathrm{mesoSiO}_{2} / \mathrm{PANs}$ are promising sensitive photoluminescence sensors of Fe(III). The study compared the sensing capabilities of CDs in solution and $\mathrm{CD} / \mathrm{mesoSiO}_{2} / \mathrm{PAN}$ nanofibers, and the latter showed higher efficiency, photoluminescence stability and improved selectivity. In Figure 2d (i) and (ii) are displayed the selectivity of CDs in solution and $\mathrm{CD} / \mathrm{mesoSiO}_{2} / \mathrm{PAN}$ nanofibers for $\mathrm{Fe}(\mathrm{III})$ detection, respectively. The selectivity was ascribed to a coordinated interaction between Fe(III) and the phenol hydroxyl groups of CDs, that brought the photoluminescence quenching signal as a function of the Fe(III) concentration, (Figure 2d (iii)), resulting from the interaction of the metal ions with oxygen in the presence of the groups of the CDs. The limit of detection of Fe(III) in aqueous solution was determined as $0.2 \mathrm{mg} \cdot \mathrm{L}^{-1}$ (Figure $2 \mathrm{~d}$ (iv)). The incorporation of CDs on the electrospun nanofibers improved the luminescence properties of CDs, and qualified the $\mathrm{CD} / \mathrm{mesoSiO}_{2} / \mathrm{PAN}$ nanofibers as a promising 'turn-off' and 'label-free' fluorescence sensor for heavy metals.

The enhanced sensitivity of electrospun nanofibers is, in general, attributed to their larger surface area compared to thin films. This improvement was confirmed by the study reported by $\mathrm{Wu}$ and coworkers [33], where a comparison between the properties of electrospun nanofibers versus dip-coating films of poly[( $N$-isopropylacrylamide)-co-( $N$-hydroxymethyl acrylamide)-co-(4-rhodamine hydrazonomethyl-3-hydroxy-phenyl methacrylate)] [poly(NIPAAm-co-NMA-co-RHPMA)-PNNR] copolymers was carried out, under the conditions of different molar ratios of NIPAAm, NMA and RHPMA monomers (PNNR1, PNNR2 and PNNR3). The latter showed a high selectivity and sensitive recognition of $\mathrm{Cu}$ (II) through fluorescence measurements (Figure 2e (i)). The increase of $\mathrm{Cu}$ (II) concentration led to a quenching of photoluminescence, which occurs due to the paramagnetic effect of the $\mathrm{d} 9$ system of the $\mathrm{Cu}$ (II) ion, which suggests a photoinduced electron transfer from singlet fluorophore (rhodamine) excited state to paramagnetic metal center. [33] The Stern-Volmer constants of PNNR copolymers in nanofibers and dip-coated films were obtained from the slopes showed in Figure 2e (ii), indicating that PNNR nanofibers have a much higher sensitivity as compared to films. The limit of detection of $\mathrm{Cu}(\mathrm{II})$ to PNNR nanofibers was determined as $6.4 \times 10^{-3} \mathrm{mg} \cdot \mathrm{L}^{-1}$. The study suggests the PNNR nanofibers have potential applications as "on-off" types of fluorescent sensors for $\mathrm{Cu}(\mathrm{II})$ ions, as well as for the application in pollutant separation and water purification. 


\subsection{Optical Detection Using Colorimetry}

As previously mentioned, the colorimetric detection of a specific analyte induces changes in the absorption band of the material, resulting in color changes that can be easily interpreted by the naked eye. As a consequence, the detection response measurement does not require complex and expensive equipment, simplifying the sensing apparatus [8,54,55]. However, the color change can be highly influenced by experimental parameters such as luminosity and visualization angle. To eliminate misrecognition, colorimetric devices have the color change followed by absorbance measurements using a standard UV-vis spectrometer [34]. Therefore, the absorbance band shift can be precisely measured and the sensor response determined according to the type and concentration of the target analyte for more accurate systems.

Organic dyes with conjugated aromatic systems have been largely employed for heavy metal detection [56,57]. The detection mechanism is pretty easy and involves the reprecipitation of the metal ions by a complexation process with the organic molecules. However, not many systems are based on NFM substrates yet, which indicates a whole world of possibility to be explored in the next years. Curcumin is one of the organic dyes employed for heavy metal detection and it is reported by Raj et al. [45] as a simple biocompatible and selective system for $\mathrm{Pb}$ (II) colorimetric detection. The strips were produced by electrospinning a composite mixture of cellulose acetate and curcumin, yielding curcumin-loaded cellulose acetate nanofibers (CC-CA). A colorimetric study was carried out at different $\mathrm{pH}$ levels for optimization of the operating conditions. The authors found out that below $\mathrm{pH} 4$, the absorbance intensity changed without visual color alteration. From $\mathrm{pH} 5$ to 11 represented better conditions without significant absorbance or color changes, and pH 5 was set as standard. The sensitivity was tested from $2.07 \times 10^{-3} \mathrm{mg} \cdot \mathrm{L}^{-1}$ to $207 \mathrm{mg} \cdot \mathrm{L}^{-1} \mathrm{of} \mathrm{Pb}(\mathrm{II})$ ions and presented a linear decrease of the absorbance, a limit of detection of $4.1 \mathrm{mg} \cdot \mathrm{L}^{-1}$ and a visual color change from yellow to orange, as displayed in Figure 3a. The color change is a result of the $\mathrm{Pb}$ (II) complexation by curcumin chelating. $\mathrm{CC}-\mathrm{CA}$ strips proved to be selective for $\mathrm{Pb}$ (II) among eight different metal ions solutions (Ba(II), Ca(II), Co(II), Cd(II), Cu(II), Mg(II), Ni(II) and Zn(II)) with $1 \mathrm{mM}$ of concentration. No color changes were observed on the CC-CA strips for ions distinct from $\mathrm{Pb}(\mathrm{II})$. The authors attributed the CC-CA strips' selectivity to the strong and stable complex formed between curcumin and $\mathrm{Pb}$ (II) ions by the $\alpha, \beta$-unsaturated $\beta$-diketo moiety. During the complexation, the enolic protons are replaced by the metallic ion, changing the electronic configuration and thus the materials' color. Saithongdee et al. [49] also studied the performance of curcumin in zein NFM strips as chemosensor and the pH influence on the Fe(II) ion detection, with optical limit of detection of $0.4 \mathrm{mg} \cdot \mathrm{L}^{-1}$ and linear visual color change with the Fe(II) ion concentration. Such results demonstrate the flexibility of the sensor's selectivity for the detection of different heavy metal ions with the same optically active species by carefully choosing the associated material.

Dimethylglyoxime (DMG) is another organic aromatic molecule, which acts by complexing palladium and nickel ions. A colorimetric sensor for $\mathrm{Ni}$ (II) detection in tap water and laboratory waste water was fabricated based on polycaprolactam nanofibers combined with dimethylglyoxime in glass slides (N6-DMG@glass) by Najarzadekan et al. [48]. The strips presented a good performance with visual color change from colorless to red in the linear range from $5 \times 10^{-3}$ to $1 \times 10^{-1} \mathrm{mg} \cdot \mathrm{L}^{-1}$ and a detection limit of $2 \times 10^{-3} \mathrm{mg} \cdot \mathrm{L}^{-1}$. However, selective tests showed significant interference for $\mathrm{Cu}$ (II) in concentrations higher than $6 \times 10^{-1} \mathrm{mg} \cdot \mathrm{L}^{-1}$ and higher than $1 \mathrm{mg} \cdot \mathrm{L}^{-1}$ for seven other ions.

Sensors fabricated with conjugated polymers have shown better performance with increased sensitivity when compared with other conjugated systems such as organic dyes. This behavior can be attributed to delocalized $\pi$-bonds in a long range which enable a faster charge transfer and an increased sensitivity. In the case of heavy-metal ion detection, conducting polymers will interact with the heavy metal ions by a redox mechanism, changing the conjugation of the bonds and consequently the material's absorbance/reflectance. This change in the oxidation degree can also lead to heavy metal ion complexation. As is known, polyaniline (PANI) is a classic conjugated polymer that, besides modulation of its properties by the oxidation degree, has amine and imine groups, which can be 
protonated and deprotonated according to the amount of available $\mathrm{H}^{+}$, resulting in different colors varying from white to blue. For example, emeraldine base (EB) is the PANI half-oxidized state and it can be converted to the emeraldine salt according to the amine and imine group interactions or in leucoemeraldine base (LB) according to the variation of the oxidation degree. For sensors fabricated with PANI, besides the oxidation process, a second mechanism take place through amine and imine group protonation. The amine and imine groups will interact with the ions, changing the doping state, and consequently the optical properties. Si et al. [47] combined the direct fabrication of conjugated polymer nanofiber membranes followed by a functionalization step to convert the optically active species to a more interesting form. Thus, the authors showed the direct interaction between PANI and $\mathrm{Hg}$ (II) ions through the fabrication of a sensitive and selective sensor based on nanofiber membranes (PANI-LBNF), as illustrated in Figure 3b. Nanofiber membranes were obtained by the electrospinning technique followed by an emeraldine base reduction to leucoemeraldine base with hydrazine vapor, and they were used as probes for specific interactions with $\mathrm{Hg}(\mathrm{II})$ ions in aqueous medium. In the presence of $\mathrm{Hg}(\mathrm{II})$, PANI-LBNF undergoes by ether a protonation and oxidation process, showing a highly selective and sensitive response with a distinct color change from white to yellow/green, green and blue according to the $\mathrm{Hg}$ (II) concentration. The sensor response based on the color change could be characterized by the intensity variation of the reflectance bands at 440 and $645 \mathrm{~nm}$. A $1.0 \times 10^{-3} \mathrm{mg} \cdot \mathrm{L}^{-1}$ concentration was the smallest concentration able to be detected with the naked eye, and was set as the sensor detection limit. The authors also used a novel colorimetric framework that can be compared to human perception to confirm the membrane color change along with the $\mathrm{Hg}(\mathrm{II})$ concentration, confirming the reliability of the PANI use for this type of detection.

Regarding inorganic materials for colorimetric applications, metallic nanoparticles are very interesting due to their size-dependent optical properties [58]. Gold nanoparticles (AuNPs) are optically active materials that have attracted great attention for heavy metal detection [59-64]. For instance, $\mathrm{Li}$ et al. [44] reported for the first time the use of nanofiber membranes as a substrate for AuNPs as optically active sensors (Figure 3c). Furthermore, the authors employed a complex functionalization with immobilized L-glutathione (GSH) along with AuNPs (Au@GSH) on the surface of nylon 6/polyvinylidene-fluoride NFM for $\mathrm{Pb}$ (II) colorimetric detection. The GSH was added with the purpose of a chelating agent and also to stabilize the AuNPs through the thiol group, forming a covalent $\mathrm{Au}-\mathrm{S}$ bond. The NFM strips decorated with Au@GSH presented a vibrant pink color due to the well-dispersed Au@GSH functionalization. Upon addition of $\mathrm{Pb}(\mathrm{II})$ aqueous solution, the strips' color changed from pink to purple due to the distance decrease among Au@GSH, as a result of the $\mathrm{Pb}$ (II) ion complexation with Au@GSH. The sensor proved to be highly sensitive even by the naked eye, with a recognition limit of $1.0 \times 10^{-1} \mathrm{mg} \cdot \mathrm{L}^{-1}$. The sensor selectivity was tested against several salts, proteins and 10 metal cations, showing no apparent response changes, proving the high specificity toward $\mathrm{Pb}(\mathrm{II})$. The selectivity was attributed to factors such as the strong ability of $\mathrm{Pb}$ (II) binding with glutathione carboxylate ions, and also, that the - $\mathrm{SH}$ groups are occupied by Au nanoparticles preventing interactions with $\mathrm{Hg}(\mathrm{II})$ ions, and the $-\mathrm{NH}_{2}$ groups are protonated due to the water $\mathrm{pH}$ used, preventing or at least decreasing considerably the binding interactions with ions such as $\mathrm{Zn}$ (II), $\mathrm{F}(\mathrm{II})$ and $\mathrm{Cd}(\mathrm{II})$. A colorimetric framework for quantitative analysis and gradient sensitivity was also carried out, confirming the color changes for a wide range of $\mathrm{Pb}$ (II) concentrations (Figure 3b (iii)). The NFM chromic strips showed a performance 28 -fold better than the paper-based one. 

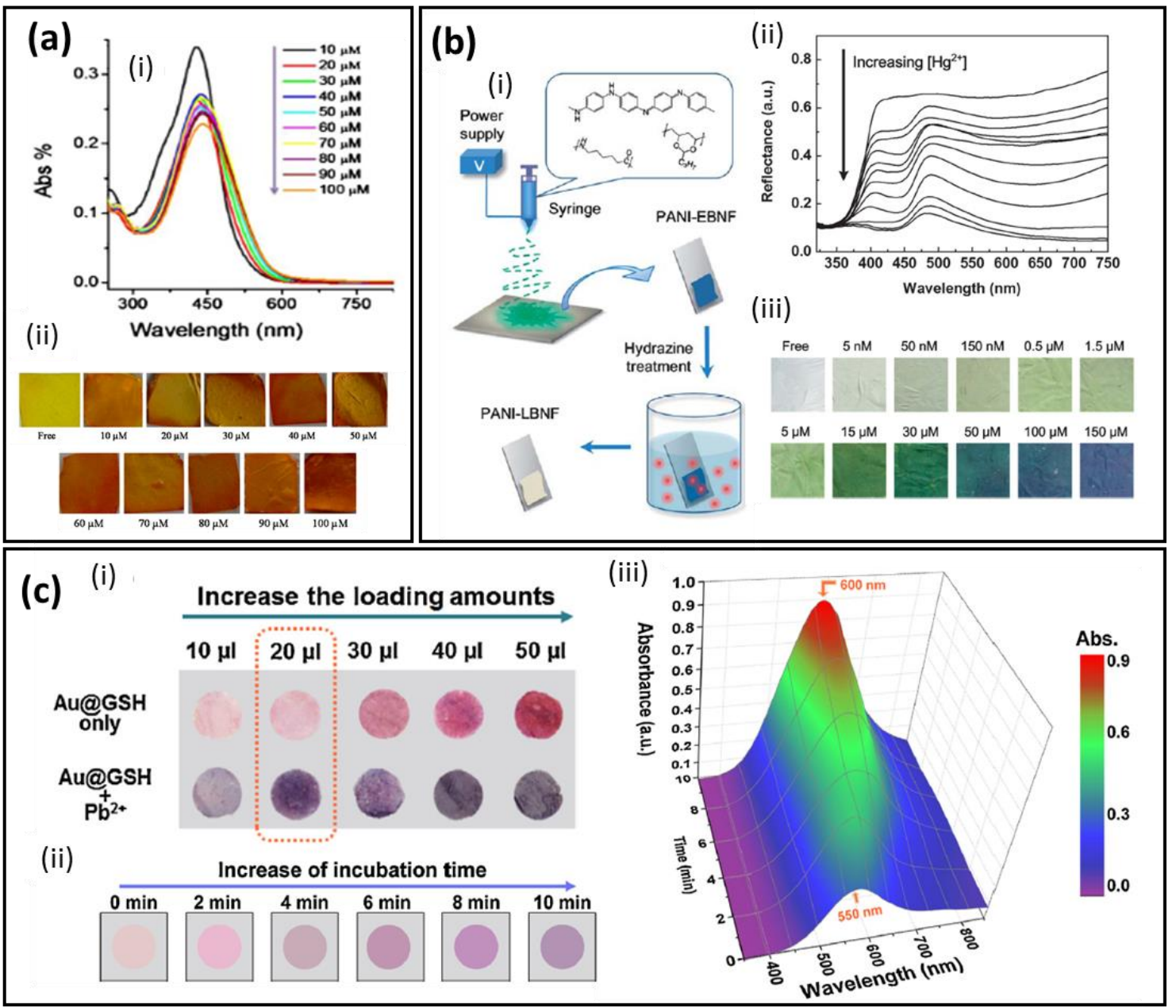

Figure 3. (a) (i) UV-vis for different concentrations of $\mathrm{Pb}$ (II) and (ii) nanofiber images showing a visual color change. Adapted and reprinted with permission from [45]. Copyright 2016 Elsevier. (b) (i) Schematic illustration of the preparation of PANI-LBNF sensing membranes by the combination of electrospinning and hydrazine treatment, (ii) reflectance spectra and (iii) optical colorimetric responses of the PANI-LBNF sensor strips after incubation in different $\mathrm{Hg}$ (II) concentrations. Adapted and reprinted with permission from [47]. Copyright 2014 Royal Society of Chemistry. (c) (i) Digital photo images of the loading optically active species amount and the corresponding samples after incubation with $\mathrm{Pb}(\mathrm{II})$, (ii) kinetic absorption response of the strips as a function of time and (iii) time-dependent visualization of $\mathrm{CIE}$ Lab color changes versus $\mathrm{Pb}$ (II) concentration. Adapted and reprinted with permission from [44]. Copyright 2014 Elsevier.

\section{Conclusions and Future Outlook}

Recent investigations reporting the use of electrospinning techniques to produce fluorescent and colorimetric electrospun nanofibers aiming at the specific detection of heavy metals were surveyed in this review article, where remarkable results for the analysis of both artificial and real samples were demonstrated. Electrospinning allows the production of nanofibers with high specific surface area, varied morphology and diameter, and the possibility of chemical functionalization. For instance, optically active ESNFs can be functionalized with metal nanoparticles, conjugated polymers and carbon-based nanomaterials, aiming at improving the sensor performance in terms of sensitivity and limit of detection towards heavy metal detection. The physicochemical properties of the nanomaterial and the polymeric matrix can be independently tailored and integrated into a single body to achieve 
an adaptable functionalization in order to obtain a high selectivity and sensitivity towards a specific heavy metal ion.

Among the several materials employed for producing optically active ESNFs, metallic and semiconducting nanoparticles appear to be the most promising, owing to the wide available chemical routes for their syntheses, facile surface chemistry, broad optical/electrical properties and low cost of production. Colorimetry and fluorescence are outstanding optical transduction mechanisms once the nanofiber membranes can have their composition modulated, according to the analyte investigated, in order to fabricate highly selective and sensitive portable sensors, enabling fast and naked-eye visual interpretation. Although electrospinning has started to move from academia to industry, some bottlenecks and pitfalls need to be solved for large-scale applications, which include: increasing the production rate of electrospun nanofibers, improving the control of processing parameters and surface modification methods, and enhancing sensor stability and limits of detection for a wide range of heavy metals. In spite of that, colorimetric and fluorescent ESNF sensors are shown to be highly suitable for real sample applications regarding heavy metal detection, and it is believed that the applications of such nanofibers in the sensors area will continue to grow in the next years.

Acknowledgments: This work was financially supported by FAPESP (Grant number: 2016/23793-4), CNPq, CAPES (PNPD20131474-33001014004P9), MCTI-SisNano and Rede Agronano (EMBRAPA) from Brazil.

Conflicts of Interest: The authors declare no conflict of interest.

\section{References}

1. Ying, Y.; Ying, W.; Li, Q.; Meng, D.; Ren, G.; Yan, R.; Peng, X. Recent advances of nanomaterial-based membrane for water purification. Appl. Mater. Today 2017, 7, 144-158. [CrossRef]

2. March, G.; Nguyen, T.D.; Piro, B. Modified electrodes used for electrochemical detection of metal ions in environmental analysis. Biosensors 2015, 5, 241-275. [CrossRef] [PubMed]

3. Kumar, P.; Kim, K.-H.; Bansal, V.; Lazarides, T.; Kumar, N. Progress in the sensing techniques for heavy metal ions using nanomaterials. J. Ind. Eng. Chem. 2017, 54, 30-43. [CrossRef]

4. Zhou, Y.; Tang, L.; Zeng, G.; Zhang, C.; Zhang, Y.; Xie, X. Current progress in biosensors for heavy metal ions based on DNAzymes/DNA molecules functionalized nanostructures: A review. Sens. Actuators B Chem. 2016, 223, 280-294. [CrossRef]

5. Pandey, S.K.; Singh, P.; Singh, J.; Sachan, S.; Srivastava, S.; Singh, S.K. Nanocarbon-based Electrochemical Detection of Heavy Metals. Electroanalysis 2016, 28, 2472-2488. [CrossRef]

6. Aragay, G.; Pons, J.; Merkoçi, A. Recent Trends in Macro-, Micro-, and Nanomaterial-Based Tools and Strategies for Heavy-Metal Detection. Chem. Rev. 2011, 111, 3433-3458. [CrossRef] [PubMed]

7. Mehta, J.; Bhardwaj, S.K.; Bhardwaj, N.; Paul, A.K.; Kumar, P.; Kim, K.H.; Deep, A. Progress in the biosensing techniques for trace-level heavy metals. Biotechnol. Adv. 2016, 34, 47-60. [CrossRef] [PubMed]

8. Li, M.; Gou, H.; Al-Ogaidi, I.; Wu, N. Nanostructured Sensors for Detection of Heavy Metals: A Review. ACS Sustain. Chem. Eng. 2013, 1, 713-723. [CrossRef]

9. Gumpu, M.B.; Sethuraman, S.; Krishnan, U.M.; Rayappan, J.B.B. A review on detection of heavy metal ions in water-An electrochemical approach. Sens. Actuators B Chem. 2015, 213, 515-533. [CrossRef]

10. Lan, L.; Yao, Y.; Ping, J.; Ying, Y. Recent Progress in Nanomaterial-Based Optical Aptamer Assay for the Detection of Food Chemical Contaminants. ACS Appl. Mater. Interfaces 2017, 9, 23287-23301. [CrossRef] [PubMed]

11. Meng, D.; Zhao, N.; Wang, Y.; Ma, M.; Fang, L.; Gu, Y.; Jia, Y.; Liu, J. On-line/on-site analysis of heavy metals in water and soils by laser induced breakdown spectroscopy. Spectrochim. Acta Part B At. Spectrosc. 2017, 137, 39-45. [CrossRef]

12. Lee, Y.-G.; Han, J.; Kwon, S.; Kang, S.; Jang, A. Development of a rotary disc voltammetric sensor system for semi-continuous and on-site measurements of $\mathrm{Pb}(\mathrm{II})$. Chemosphere 2016, 143, 78-84. [CrossRef] [PubMed]

13. Guo, J.; Zhou, M.; Yang, C. Fluorescent hydrogel waveguide for on-site detection of heavy metal ions. Sci. Rep. 2017, 7, 7902. [CrossRef] [PubMed] 
14. Choi, S.J.; Persano, L.; Camposeo, A.; Jang, J.S.; Koo, W.T.; Kim, S.J.; Cho, H.J.; Kim, I.D.; Pisignano, D. Electrospun Nanostructures for High Performance Chemiresistive and Optical Sensors. Macromol. Mater. Eng. 2017, 302, 1-37. [CrossRef]

15. Zhang, N.; Qiao, R.; Su, J.; Yan, J.; Xie, Z.; Qiao, Y.; Wang, X.; Zhong, J. Recent Advances of Electrospun Nanofibrous Membranes in the Development of Chemosensors for Heavy Metal Detection. Small 2017, 13, 1604293. [CrossRef] [PubMed]

16. Schoolaert, E.; Hoogenboom, R.; De Clerck, K. Colorimetric Nanofibers as Optical Sensors. Adv. Funct. Mater. 2017. [CrossRef]

17. Piriya, V.S.A.; Joseph, P.; Daniel, S.C.G.K.; Lakshmanan, S.; Kinoshita, T.; Muthusamy, S. Colorimetric sensors for rapid detection of various analytes. Mater. Sci. Eng. C 2017, 78, 1231-1245. [CrossRef] [PubMed]

18. Mcdonagh, C.; Burke, C.S.; Maccraith, B.D. Optical Chemical Sensors. Chem. Rev. 2008, 353, 400-422. [CrossRef] [PubMed]

19. Spricigo, P.C.; Foschini, M.M.; Ribeiro, C.; Corrêa, D.S.; Ferreira, M.D. Nanoscaled Platforms Based on $\mathrm{SiO}_{2}$ and $\mathrm{Al}_{2} \mathrm{O}_{3}$ Impregnated with Potassium Permanganate Use Color Changes to Indicate Ethylene Removal. Food Bioprocess Technol. 2017, 10, 1622-1630. [CrossRef]

20. Mercante, L.A.; Scagion, V.P.; Migliorini, F.L.; Mattoso, L.H.C.; Correa, D.S. Electrospinning-based (bio)sensors for food and agricultural applications: A review. Trends Anal. Chem. 2017, 91, 2017. [CrossRef]

21. Roque, A.P.; Mercante, L.A.; Scagion, V.P.; Oliveira, J.E.; Mattoso, L.H.C.; De Boni, L.; Mendonca, C.R.; Correa, D.S. Fluorescent PMMA/MEH-PPV electrospun nanofibers: Investigation of morphology, solvent, and surfactant effect. J. Polym. Sci. Part B Polym. Phys. 2014, 52, 1388-1394. [CrossRef]

22. Terra, I.A.A.; Sanfelice, R.C.; Valente, G.T.; Correa, D.S. Optical sensor based on fluorescent PMMA/PFO electrospun nanofibers for monitoring volatile organic compounds. J. Appl. Polym. Sci. 2018. [CrossRef]

23. Korent Urek, Š.; Frančič, N.; Turel, M.; Lobnik, A. Sensing heavy metals using mesoporous-based optical chemical sensors. J. Nanomater. 2013, 2013. [CrossRef]

24. Senthamizhan, A.; Celebioglu, A.; Uyar, T. Real-time selective visual monitoring of $\mathrm{Hg}^{2+}$ detection at ppt level: An approach to lighting electrospun nanofibers using gold nanoclusters. Sci. Rep. 2015, 5, 10403. [CrossRef] [PubMed]

25. Kacmaz, S.; Ertekin, K.; Suslu, A.; Ergun, Y.; Celik, E.; Cocen, U. Sub-nanomolar sensing of ionic mercury with polymeric electrospun nanofibers. Mater. Chem. Phys. 2012, 133, 547-552. [CrossRef]

26. Liang, F.-C.; Kuo, C.-C.; Chen, B.-Y.; Cho, C.-J.; Hung, C.-C.; Chen, W.-C.; Borsali, R. RGB-Switchable Porous Electrospun Nanofiber Chemoprobe-Filter Prepared from Multifunctional Copolymers for Versatile Sensing of pH and Heavy Metals. ACS Appl. Mater. Interfaces 2017, 9, 16381-16396. [CrossRef] [PubMed]

27. Ma, L.; Liu, K.; Yin, M.; Chang, J.; Geng, Y.; Pan, K. Fluorescent nanofibrous membrane (FNFM) for the detection of mercuric ion (II) with high sensitivity and selectivity. Sens. Actuators B Chem. 2017, 238, 120-127. [CrossRef]

28. Liang, F.-C.; Luo, Y.-L.; Kuo, C.-C.; Chen, B.-Y.; Cho, C.-J.; Lin, F.-J.; Yu, Y.-Y.; Borsali, R. Novel Magnet and Thermoresponsive Chemosensory Electrospinning Fluorescent Nanofibers and Their Sensing Capability for Metal Ions. Polymers 2017, 9, 136. [CrossRef]

29. Li, S.; Zhou, S.; Xu, H.; Xiao, L.; Wang, Y.; Shen, H.; Wang, H.; Yuan, Q. Luminescent properties and sensing performance of a carbon quantum dot encapsulated mesoporous silica/polyacrylonitrile electrospun nanofibrous membrane. J. Mater. Sci. 2016, 51, 6801-6811. [CrossRef]

30. Chen, B.-Y.; Kuo, C.-C.; Huang, Y.-S.; Lu, S.-T.; Liang, F.-C.; Jiang, D.-H. Novel Highly Selective and Reversible Chemosensors Based on Dual-Ratiometric Fluorescent Electrospun Nanofibers with pH- and $\mathrm{Fe}^{3+}$-Modulated Multicolor Fluorescence Emission. ACS Appl. Mater. Interfaces 2015, 7, 2797-2808. [CrossRef] [PubMed]

31. Adewuyi, S.; Ondigo, D.A.; Zugle, R.; Tshentu, Z.; Nyokong, T.; Torto, N. A highly selective and sensitive pyridylazo-2-naphthol-poly(acrylic acid) functionalized electrospun nanofiber fluorescence "turn-off" chemosensory system for $\mathrm{Ni}^{2+}$. Anal. Methods 2012, 4, 1729. [CrossRef]

32. Wang, Y.; Zhu, Y.; Huang, J.; Cai, J.; Zhu, J.; Yang, X.; Shen, J.; Li, C. Perovskite quantum dots encapsulated in electrospun fiber membranes as multifunctional supersensitive sensors for biomolecules, metal ions and $\mathrm{pH}$. Nanoscale Horiz. 2017, 2, 225-232. [CrossRef]

33. Wu, W.C.; Lai, H.J. Preparation of thermo-responsive electrospun nanofibers containing rhodamine-based fluorescent sensor for $\mathrm{Cu}^{2+}$ detection. J. Polym. Res. 2016, 23. [CrossRef] 
34. Senthamizhan, A.; Celebioglu, A.; Balusamy, B.; Uyar, T. Immobilization of gold nanoclusters inside porous electrospun fibers for selective detection of $\mathrm{Cu}(\mathrm{II})$ : A strategic approach to shielding pristine performance. Sci. Rep. 2015, 5, 15608. [CrossRef] [PubMed]

35. Wang, W.; Wang, X.; Yang, Q.; Fei, X.; Sun, M.; Song, Y. A reusable nanofibrous film chemosensor for highly selective and sensitive optical signaling of $\mathrm{Cu}^{2+}$ in aqueous media. Chem. Commun. 2013, 49, 4833. [CrossRef] [PubMed]

36. Lin, H.-J.; Chen, C.-Y. Thermo-responsive electrospun nanofibers doped with 1,10-phenanthroline-based fluorescent sensor for metal ion detection. J. Mater. Sci. 2016, 51, 1620-1631. [CrossRef]

37. Kim, C.; Hwang, J.Y.; Ku, K.S.; Angupillai, S.; Son, Y.A. A renovation of non-aqueous $\mathrm{Al}^{3+}$ sensor to aqueous media sensor by simple recyclable immobilize electrospun nano-fibers and its uses for live sample analysis. Sens. Actuators B Chem. 2016, 228, 259-269. [CrossRef]

38. Wang, M.; Meng, G.; Huang, Q.; Qian, Y. Electrospun 1,4-DHAQ-doped cellulose nanofiber films for reusable fluorescence detection of trace $\mathrm{Cu}^{2+}$ and further for $\mathrm{Cr}^{3+}$. Environ. Sci. Technol. 2012, 46, 367-373. [CrossRef] [PubMed]

39. Anzenbacher, P.; Li, F.; Palacios, M.A. Toward wearable sensors: Fluorescent attoreactor mats as optically encoded cross-reactive sensor arrays. Angew. Chem. Int. Ed. 2012, 51, 2345-2348. [CrossRef]

40. Wei, Z.; Zhao, H.; Zhang, J.; Deng, L.; Wu, S.; He, J.; Dong, A. Poly(vinyl alcohol) electrospun nanofibrous membrane modified with spirolactam-rhodamine derivatives for visible detection and removal of metal ions. RSC Adv. 2014, 4, 51381-51388. [CrossRef]

41. Zhang, H.; Cao, M.; Wu, W.; Xu, H.; Cheng, S.; Fan, L.-J. Polyacrylonitrile/noble metal/SiO 2 nanofibers as substrates for the amplified detection of picomolar amounts of metal ions through plasmon-enhanced fluorescence. Nanoscale 2015, 7, 1374-1382. [CrossRef] [PubMed]

42. Li, Y.; Wen, Y.; Wang, L.; He, J.; Al-Deyab, S.S.; El-Newehy, M.; Yu, J.; Ding, B. Simultaneous visual detection and removal of lead(II) ions with pyromellitic dianhydride-grafted cellulose nanofibrous membranes. J. Mater. Chem. A 2015, 3, 18180-18189. [CrossRef]

43. Li, Y.; Wang, L.; Yin, X.; Ding, B.; Sun, G.; Ke, T.; Chen, J.; Yu, J. Colorimetric strips for visual lead ion recognition utilizing polydiacetylene embedded nanofibers. J. Mater. Chem. A 2014, 2, 18304-18312. [CrossRef]

44. Li, Y.; Ding, B.; Sun, G.; Ke, T.; Chen, J.; Al-Deyab, S.S.; Yu, J. Solid-phase pink-to-purple chromatic strips utilizing gold probes and nanofibrous membranes combined system for lead (II) assaying. Sens. Actuators $B$ Chem. 2014, 204, 673-681. [CrossRef]

45. Raj, S.; Shankaran, D.R. Curcumin based biocompatible nanofibers for lead ion detection. Sens. Actuators $B$ Chem. 2016, 226, 318-325. [CrossRef]

46. Senthamizhan, A.; Celebioglu, A.; Uyar, T. Flexible and highly stable electrospun nanofibrous membrane incorporating gold nanoclusters as an efficient probe for visual colorimetric detection of $\mathrm{Hg}(\mathrm{II})$. J. Mater. Chem. A 2014, 2, 12717-12723. [CrossRef]

47. Si, Y.; Wang, X.; Li, Y.; Chen, K.; Wang, J.; Yu, J.; Wang, H.; Ding, B. Optimized colorimetric sensor strip for mercury(II) assay using hierarchical nanostructured conjugated polymers. J. Mater. Chem. A 2014, 2, 645-652. [CrossRef]

48. Najarzadekan, H.; Sereshti, H. Development of a colorimetric sensor for nickel ion based on transparent electrospun composite nanofibers of polycaprolactam-dimethylglyoxime/polyvinyl alcohol. J. Mater. Sci. 2016, 51, 8645-8654. [CrossRef]

49. Saithongdee, A.; Praphairaksit, N.; Imyim, A. Electrospun curcumin-loaded zein membrane for iron(III) ions sensing. Sens. Actuators B Chem. 2014, 202, 935-940. [CrossRef]

50. Ondigo, D.A.; Tshentu, Z.R.; Torto, N. Electrospun nanofiber based colorimetric probe for rapid detection of $\mathrm{Fe}^{2+}$ in water. Anal. Chim. Acta 2013, 804, 228-234. [CrossRef] [PubMed]

51. Lakowicz, J.R. Principles of Fluorescence Spectroscopy, 3rd ed.; Springer International Publishing: Baltimore, MD, USA, 2006.

52. Zhang, J.; Cheng, F.; Li, J.; Zhu, J.-J.; Lu, Y. Fluorescent nanoprobes for sensing and imaging of metal ions: Recent advances and future perspectives. Nano Today 2016, 11, 309-329. [CrossRef] [PubMed]

53. Escudero, A.; Becerro, A.I.; Carrillo-Carrión, C.; Núñez, N.O.; Zyuzin, M.V.; Laguna, M.; González-Mancebo, D.; Ocaña, M.; Parak, W.J. Rare earth based nanostructured materials: Synthesis, functionalization, properties and bioimaging and biosensing applications. Nanophotonics 2017, 6. [CrossRef] 
54. Lim, S.H.; Kemling, J.W.; Feng, L.; Suslick, K.S. A colorimetric sensor array of porous pigments. Analyst 2009, 134, 2453-2457. [CrossRef] [PubMed]

55. Zhang, X.; Yin, J.; Yoon, J. Recent Advances in Development of Chiral Fluorescent and Colorimetric Sensors. Chem. Rev. 2014, 114, 4918-4959. [CrossRef] [PubMed]

56. Hadar, H.A.; Bulatov, V.; Dolgin, B.; Schechter, I. Detection of heavy metals in water using dye nano-complexants and a polymeric film. J. Hazard. Mater. 2013, 260, 652-659. [CrossRef] [PubMed]

57. Takahashi, Y.; Kasai, H.; Nakanishi, H.; Suzuki, T.M. Test Strips for Heavy-Metal Ions Fabricated from Nanosized Dye Compounds. Angew. Chem. Int. Ed. 2006, 45, 913-916. [CrossRef] [PubMed]

58. Priyadarshini, E.; Pradhan, N. Gold nanoparticles as efficient sensors in colorimetric detection of toxic metal ions: A review. Sens. Actuators B Chem. 2017, 238, 888-902. [CrossRef]

59. Alex, S.A.; Chandrasekaran, N.; Mukherjee, A. State-of-the-art strategies for the colorimetric detection of heavy metals using gold nanorods based on aspect ratio reduction. Anal. Methods 2016, 8, 2131-2137. [CrossRef]

60. Guo, L.; Xu, Y.; Ferhan, A.R.; Chen, G.; Kim, D.-H. Oriented Gold Nanoparticle Aggregation for Colorimetric Sensors with Surprisingly High Analytical Figures of Merit. J. Am. Chem. Soc. 2013, 135, 12338-12345. [CrossRef] [PubMed]

61. Vilela, D.; González, M.C.; Escarpa, A. Sensing colorimetric approaches based on gold and silver nanoparticles aggregation: Chemicasl creativity behind the assay. A review. Anal. Chim. Acta 2012, 751, 24-43. [CrossRef] [PubMed]

62. Sener, G.; Uzun, L.; Denizli, A. Colorimetric Sensor Array Based on Gold Nanoparticles and Amino Acids for Identification of Toxic Metal Ions in Water. ACS Appl. Mater. Interfaces 2014, 6, 18395-18400. [CrossRef] [PubMed]

63. Ye, S.; Shi, X.; Gu, W.; Zhang, Y.; Xian, Y. A colorimetric sensor based on catechol-terminated mixed self-assembled monolayers modified gold nanoparticles for ultrasensitive detections of copper ions. Analyst 2012, 137, 3365-3371. [CrossRef] [PubMed]

64. Huang, C.-C.; Chang, H.-T. Parameters for selective colorimetric sensing of mercury(II) in aqueous solutions using mercaptopropionic acid-modified gold nanoparticles. Chem. Commun. 2007, 1215-1217. [CrossRef] [PubMed]

(C) 2017 by the authors. Licensee MDPI, Basel, Switzerland. This article is an open access article distributed under the terms and conditions of the Creative Commons Attribution (CC BY) license (http://creativecommons.org/licenses/by/4.0/). 